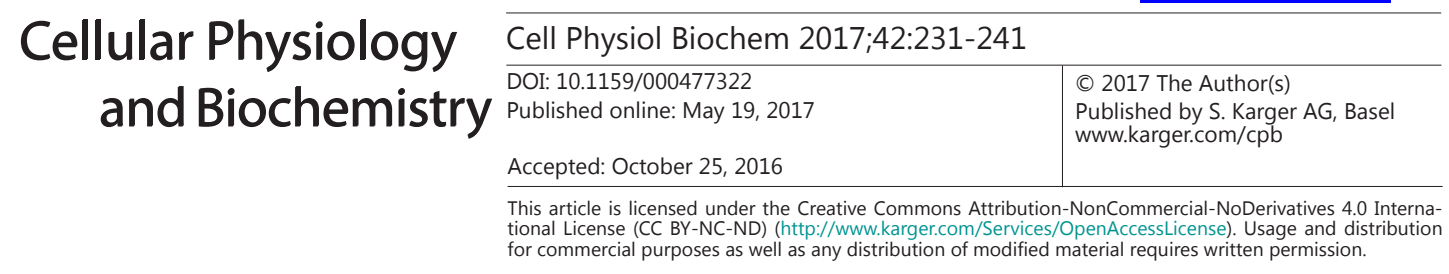

\title{
The Role of 5-HTR6 in Mossy Fiber Sprouting: Activating Fyn and p-ERK1/2 in Pilocarpine-Induced Chronic Epileptic Rats
}

\author{
Wanhui Lin ${ }^{\mathrm{a}, \mathrm{d}}$ Wenli Huang ${ }^{\mathrm{a}}$ Shenggen Chen ${ }^{\mathrm{a}}$ Mingxing Lin ${ }^{\mathrm{b}}$ Qingyu Huang ${ }^{\mathrm{a}}$ \\ Huapin Huang ${ }^{c}$ \\ aDepartment of Neurology, Fujian Medical University Union Hospital, bepartment of Pediatrics, Fujian \\ Medical University Union Hospital, 'Department of Neurology Fujian Medical University Union Hospital, \\ Fujian Key Laboratory of Molecular Neurology, dDepartment of Geriatrics, Fujian Medical University \\ Union Hospital, Fuzhou, China
}

\section{Key Words}

5-HTR6 • Mossy fiber sprouting (MFS) • Fyn • p-ERK1/2 • GAP-43

\begin{abstract}
Objective: Our primary objective is to verify whether 5-HTR6 is involved in the development of mossy fiber sprouting (MFS), and to determine how the progression of MFS is affected by 5-HTR6. Methods: A total of 90 male adult Sprague-Dawley rats were allocated into either the control group $(n=36)$ or the epileptic group $(n=54)$. Status epilepticus (SE) of rats was induced by the intraperitoneal (i.p.) injection of $\mathrm{LiCl}$-pilocarpine. We conducted our experiments in two stages. The first stage involves equally dividing 36 epileptic rats into three groups with treatments of none, 5-HTR6 antagonist SB-27104 (SB) and vehicle DMSO. Then behavior and electroencephalogram (EEG) of rats were monitored by video-EEG. The second stage involves dividing 126 epileptic rats into seven groups with treatments of none, 10\% DMSO, SB (100 $\mu \mathrm{g} / \mathrm{kg})$, Fyn antagonist PP $2(50 \mu \mathrm{g} / \mathrm{kg}), \mathrm{p}$-ERK1/2 antagonist PD-98059 $(30 \mu \mathrm{g} / \mathrm{kg}), \mathrm{SB}(100 \mu \mathrm{g} /$ $\mathrm{kg})+\mathrm{PP}_{2}(50 \mu \mathrm{g} / \mathrm{kg}) ; \mathrm{SB}(100 \mu \mathrm{g} / \mathrm{kg})+\mathrm{PD}-98059(30 \mu \mathrm{g} / \mathrm{kg})$. We also treated 18 rats in the control group of the first stage with $100 \mu \mathrm{g} / \mathrm{kg} 5-\mathrm{HTR} 6$ agonist WAY-181187 (WAY). MFS of rats was detected through the approach of Timm's staining. Finally, expressions of 5-HTR6, Fyn, p-ERK1/2 and GAP-3 were qualified and semi-quantified via western blotting or RT-PCR. Results: Induction of SE could stimulate formation of MFS and increased GAP-43 expressions. Expressions of 5-HTR6, Fyn and p-ERK1/2 were also up-regulated with increasing time after establishment of SE models. The development of MFS was remarkably inhibited by $\mathrm{SB}_{1} \mathrm{PP}_{2}$ and PD. Compared to the single antagonist, such an inhibitory effect was enhanced by SB+PD or $\mathrm{SB}+\mathrm{PP}$. Moreover, treatment of healthy rats with WAY would contribute to up-regulated Fyn and $\mathrm{p}$-ERK1/2 expressions, as well as development of MFS $(P<0.05)$. Suppression of Fyn triggered a down-regulating trend of p-ERK1/2 $(P<0.05)$, however, suppressed p-ERK1/2 did not have such a significant effect on Fyn expression. Conclusion: HTR6 may affect the progression of MFS by activating both p-ERK1/2 and Fyn, which further modulate the expression of GAP-43.

W. Lin and W. Huang contributed equally to this work. 


\section{Introduction}

Mossy fiber sprouting (MFS) in hippocampus is often observed in patients with temporal lobe epilepsy and its severity is positively correlated to the frequency of recurrent spontaneous seizures (SRSs). Abnormal axon growth and synaptic plasticity resulted from epileptiform discharge are two potential causes of MFS [1, 2]. Besides that, several molecular mechanisms are linked with the progression of MFS, such as GSK-3 $\beta /$ p-GSK-3 $\beta$ and mammalian target of rapamycin (mTOR) signal pathway [3, 4].

The mTOR pathway therein has been verified to be involved in modifying seizure activity through cooperation with 5-hydroxytryptamine receptor 6 (HTR6) [5]. HTR6 belonged to the serotonin receptor (5-HTR) which coordinated with brain serotonin to suppress the threshold of seizures [6-8]. Additionally, MFS appeared to be associated with 5-HTR which has been confirmed to facilitate synaptic enhancement $[9,10]$. HTR6 was exclusively expressed in the central nervous system (e.g. cerebral cortex, hippocampus, striatum and olfactory tubercle) and it was able to modulate the release of neurotransmitters (e.g. acetylcholine and glutamate) which potentially caused neurological diseases (e.g. depression and anxiety) [11-13]. Researchers also suggested that HTR6 may exhibit clinical significance for patients with neurological disorders, for instance, HTR6 ligands has been explored as a solution for Alzheimer's disease and the corresponding results have been progressed to phase II trials [14]. Animal experiments also suggested that selective HTR6 antagonists (i.e. SB-399885, SB-271046, SB-258510 and Ro-258510) could improve the threshold of seizures in rats [15]. Generally speaking, HTR6 and seizures were inextricably linked, though in-depth mechanisms were still in a groping stage.

In fact, HTR6 was able to mobilize extracellular signal regulated kinase1/2 (ERK1/2) through interaction with tyrosine kinase Fyn [16]. It was documented that knockout of Fyn within the rat models could trigger increased acquisition of long-term potentiation and contribute to epilepsy kindling [16, 17]. Furthermore, phosphorylated ERK1/2 (p-ERK1/2) also seemed to play a crucial role in synapse reorganization by activating the transcription factor C-fos, which was involved not merely in repairing nerve trauma (e.g. nerve regeneration), but also in promoting axon growth and synaptic plasticity through targeting growth associated protein 43 (GAP-43) [18-21]. Therefore, we proposed a hypothesis that HTR6 may be able to stimulate epilepsy-induced MFS by activating Fyn, ERK1/2 and GAP-43 $[21,22]$.

Above all, the primary objective of our study is to verify whether selective HTR6 antagonist SB-271046 is able to alleviate seizures resulted from pilocarpine-induced chronic epilepsy. Apart from that, we are interested in finding if ERK1/2 or Fyn is involved in the progression of MFS.

\section{Materials and Methods}

\section{Inducing Chronic Epilepsy in rats by using Pilocarpine}

We put male adult Sprague-Dawley rats (weight: 200-250 g, age: 10-13 weeks old) into a room where temperature $\left(22-26^{\circ} \mathrm{C}\right)$, humidity $(50 \pm 5 \%)$ and dark/light cycle $(12 \mathrm{~h}: 12 \mathrm{~h})$ were controlled. All rats in the room had free access to food and water. We conducted our experiments in two stages. The first stage involved randomly allocating 90 rats into the control $(n=36)$ and status epilepticus (SE) group $(n=54)$. Subsequently, Then surface electrodes were implanted into the skull of rats that were subject to anesthesia (injection of $10 \%$ chloralhydrate). Altogether three electrodes were, respectively, implanted above the frontal cortex [AP $2.5 \mathrm{~mm}, \mathrm{ML} 2.0 \mathrm{~mm}$ and DV $0.5 \mathrm{~mm}$ ], on the surface of the skull as a ground and behind the ear as a reference. Gentamycin was intraperitoneally (i.p.) injected into rats for infection prevention and rats were allowed for a recovery period of one week. Finally, rats were injected with pilocarpine $(30 \mathrm{mg} / \mathrm{kg}$, i.p.; Sigma), followed by treatment with lithium chloride (127 mg/kg i.p.; Sigma) for 16-18 h. The activity of induced seizures was evaluated according to the Racine's score [23]. If stage-IV or stage-V seizures were reflected in rats for more than one hour, diazepam ( $5 \mathrm{mg} / \mathrm{kg}$; i.p.) was used to terminate SE so that these 


\section{Cellular Physiology Cell Physiol Biochem 2017;42:231-241

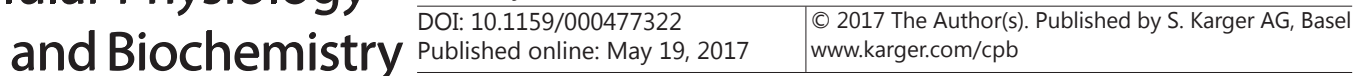

Lin et al.: 5-HTR6 Activated Fyn/p-ERK1/2 Pathway in Chronic Epileptic

rats can be used for subsequent experiments. The corresponding behavior and electroencephalogram (EEG) of rats were constantly monitored utilizing the EEG monitoring system (BYOPAC system, MP 36, USA). The intraventricular cannulas were bilaterally placed in rats for monitoring their hippocampi. The above monitoring process was carried out for 15 hours per day over a period of four weeks. Spontaneous recurrent seizures (SRSs) were evaluated based on their corresponding frequency (per week) and stage over the chronic epilepsy period [24].

\section{Drug Intervention}

The second stage of the experiment involves randomly dividing 126 rats with induced SE into seven sub-groups ( $\mathrm{n}=18$ for each group). After successful induction of SE for three days, rats were anesthetized through injection of $10 \%$ chloralhydrate $(300 \mathrm{mg} / \mathrm{kg}$, i.p.), and were then placed in a stereotaxic frame as described by the research reported by Paxinos and Watsonatlas [25]. A small-gauge stainless steel guided cannula was inserted into the lateral ventricle (AP, $-1.0 \mathrm{~mm}, \mathrm{~L},+1.5 \mathrm{~mm}, \mathrm{~V},+3.3 \mathrm{~mm}$ ) of each rat after their skulls were cleaned and disinfected. The seven sub-groups were, respectively, given interventions of none, 10\% DMSO, equivalent volumes of $100 \mu \mathrm{g} / \mathrm{kg}$ 5-HTR6 antagonist SB-271046 (SB), $50 \mu \mathrm{g} / \mathrm{kg}$ Fyn antagonist $\mathrm{PP}_{2}\left(\mathrm{PP}_{2}\right), 30 \mu \mathrm{g} / \mathrm{kg}$ p-ERK1/2 antagonist PD-98059 (PD), $100 \mu \mathrm{g} / \mathrm{kg} \mathrm{SB}-271046+50 \mu \mathrm{g} / \mathrm{kg} \mathrm{PP}_{2}\left(\mathrm{SB}+\mathrm{PP}_{2}\right)$ and $100 \mu \mathrm{g} / \mathrm{kg} \mathrm{SB}-271046+30 \mu \mathrm{g} / \mathrm{kg}$ PD-98059(SB+PD). Another 18 healthy rats taken from the control group of the first-stage experiment were intervened with $100 \mu \mathrm{g} / \mathrm{kg}$ 5-HTR6 agonist WAY-181187 (WAY). All the above substances were dissolved in DMSO. The 10\% DMSO or other artificial cerebrospinal fluids were given through the cannula once per day at 14:00-16:00 for a period of one week. Injections were implemented at the rate of $1 \mu \mathrm{l}$ per min with a resting period of $1 \mathrm{~min}$ between successive injections. Bucinnazine was given to each rat during the operation for pain relief.

\section{Timm's Staining}

Rats that were used in the first stage were sacrificed at different times $\left(1^{\text {st }}, 2^{\text {nd }}, 3^{\text {rd }}\right.$ and $4^{\text {th }}$ week after SE operation), whereas rats in the second stage were sacrificed in the $4^{\text {th }}$ week following the operation of SE. Blinding procedures were strictly followed by individuals who scored the Timm's staining slides for rats in each group. Once deep anesthesia was achieved by using $10 \%$ chloralhydrate (300 mg/kg, i.p.), rats were transcardially perfused with $200 \mathrm{ml} 0.4 \%$ sodium sulfide perfusion medium which was followed

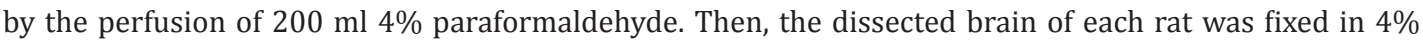
paraformaldehyde for one night and transferred into $30 \%$ sucrose solution for $48 \mathrm{~h}$. The resulting brain was embedded in frozen tissue medium by using a freezing microtome and tissue sections (30 $\mu \mathrm{m}$ thick) containing the hippocampus were cut on a cryostat. The corresponding sections were immersed in a specific

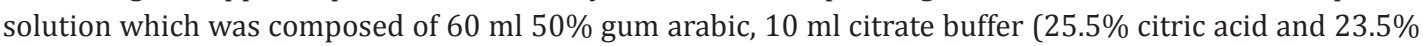

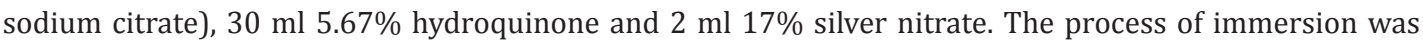
carried out in the dark for $90 \mathrm{~min}$. After the immersed sections were washed, they were dehydrated by using graded ethanol solutions, cleared with xylene and mounted with Permount. Finally, a Leica microscope was used to observe the sections. We calculated the corresponding Timm's score for the CA3 region in the hippocampus based on the following criteria: 1) 0 score if no granules in the stratum pyramidale or stratum oriens were found along the portion of the CA3 sub-region; 2) 1 score when sparse granules were present in discrete bundles; 3) 2 scores when moderate granules were found; 4) 3 scores if prominent granules were observed; 5) 4 scores if prominent granules accompanied with near-continuous distribution were displayed along the entire CA3 region; 6) 5 scores when continuous or near-continuous dense laminar band of granules were observed along the entire CA3 region [26].

\section{Western Blotting}

Rats which were used in the first stage were sacrificed at different times (1, 2, 3 and 4 weeks after SE operation), whereas rats in the second stage were sacrificed in the $4^{\text {th }}$ week following the operation of SE. Once deep anesthesia was achieved by using $10 \%$ chloralhydrate $(300 \mathrm{mg} / \mathrm{kg}$, i.p.), rats were transcardially perfused with $200 \mathrm{ml} 0.01 \mathrm{M}$ Phosphate-buffered saline (PBS). Hippocampal tissues were separated and then were stored in the $-80{ }^{\circ} \mathrm{C}$ refrigerator for subsequent experiments. Proteins extracted from hippocampal tissues were separated by using sodium dodecyl sulfate polyacrylamide gel electrophoresis (SDS-PAGE) and were transferred to nitrocellulose membranes. Membranes which had been blocked with 5\% skim milk for two hours at room temperature were subject to the incubation with primary antibodies against the 


\section{Cellular Physiology Cell Physiol Biochem 2017;42:231-241 \begin{tabular}{l|l} 
and Biochemistry Published online:IMay 19, 2017 & $\begin{array}{l}\text { D } 2017 \text { The Author(s). Published by S. Karger AG, Basel } \\
\text { www.karger.com/cpb }\end{array}$
\end{tabular}}

Lin et al.: 5-HTR6 Activated Fyn/p-ERK1/2 Pathway in Chronic Epileptic

following proteins: HTR6 (1:1000, Sigma); Fyn (1:800, Sigma); p-ERK1/2 (1:1500, Sigma); ERK1/2 (1:1500, Sigma) and GAPDH (1:1000, Shanghai, China). After that, the resulting membranes were washed by using Tris Buffered Saline Tween (TBST) and were incubated with peroxidase-conjugated secondary antibodies. Specific bands were detected by using an electrochemiluminescence (ECL) system and the intensity of signals was analyzed by using the Image J software.

$R T-P C R$

Total RNA was isolated from bilateral hippocampal tissues and the expression of GAP-43 was detected. Each sample includes two hippocampi of one rat. The primer sequences of GAP-43 and GAPDH used in this experiment were shown as: GAP-43 (forward: GGCTCATAAGGCTGCAAAT, reverse: CCATCTCCCTCCTTCTCCACA) and GAPDH (forward: ACAGCAACAGGGTGGTGGAC, reverse: TTTGAGGGTGCAGCGAACTT). Total RNA was reversely transcribed into cDNA and amplified by using an Applied Biosystems thermal cycler (Foster City, CA). GAPDH was used as the reference gene. Each sample was measured in three replicates and the mean threshold cycle $(\mathrm{Ct})$ number was evaluated for each sample.

Statistical Analysis

All statistical analyses were performed with SPSS 18.0 software (Illinois, USA). Data were presented as mean \pm SD or median (range) calculated from at least three experiments. The two-tailed student's $t$-test or one-way Analysis of Variance (ANOVA) was used to analyze between-group comparisons. Alternatively, the non-parametric rank tests were conducted to identify differences in Timm's score among various intervention groups. A $P$-value $<0.05$ was considered as significant for all statistical tests. Categorical data were analyzed by using Chi-square test. Multiple comparisons after the hypothesis testing were conducted based on the Fisher's partial least squares difference (LSD) test with the assumption of homogeneous variance, and the Tamhane's method was followed in the case of heterogeneous variance.

\section{Results}

Behavioral Changes of Rats with Chronic Epilepsy

SE was triggered in rats approximately 20 minutes after injection of pilocarpine. Then the rats experienced a quiescent phase that continued for 2-7 days. During this period, rats behaved normally, yet with reduced appetite and decreased activity. Their EEG results (Fig. 1A-D) and SRS activities were observed 14-28 days after successful induction of SE. Compared to the SE group, both the frequency (Fig. 1E) and stage of SRSs (Table 1) in the $\mathrm{SE}+\mathrm{SB}$ group were significantly decreased $(P<0.05)$.

MFS and GAP-43 mRNA Expressions at Different Time Points after Induction of SE

The brown granules occasionally appeared in the stratum pyramidale or stratum oriens in healthy rats, however, they became increasingly obvious over time after SE operation (Fig. 2A). Similarly, MFS score was significantly increased in the SE-2W and SE-4W group when compared with the SE-1W group $(P<0.01)$, but no significant difference of MFS score was observed between the SE-2W and SE-4W group (Fig. 2B). Besides, RT-PCR analysis showed that the expression of GAP-43 mRNA after SE operation increased significantly and achieved the higher at week 2 and week 4 when compared with that detected at week $1(P<0.01)$ (Fig. 2C).

Table 1. Comparisons of mean attack stages of SRS in the chronic period among groups of control, SE, SE+DMSO and SE+SB. SRS: spontaneous recurrent seizure; SE: status epilepticus; DMSO: dimethylsulfoxide; SB: SB-271046; ${ }^{* *}: P<0.01$

\begin{tabular}{ccccccccc}
\hline \multirow{2}{*}{ The stages of SRS } & \multicolumn{4}{c}{ Treatments } & \multicolumn{2}{c}{ SE vs. SE +DMSO } & \multicolumn{2}{c}{ SE vs. SE +SB } \\
& Control & SE & SE +DMSO & SE+SB & $\chi^{2}$ & $P$ & $\chi^{2}$ & $P$ \\
\hline I & 0 & 1 & 1 & 9 & & & & \\
II & 0 & 12 & 13 & 9 & 0.151 & 0.927 & 11.83 & $0.003^{*}$ \\
III & 0 & 5 & 4 & 0 & & & & \\
\hline
\end{tabular}




\section{A}

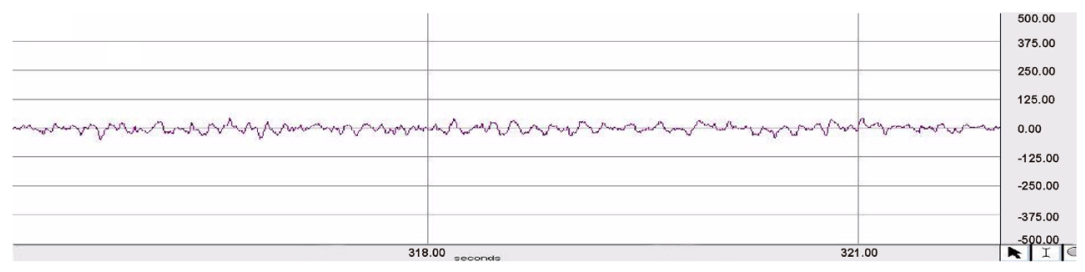

B

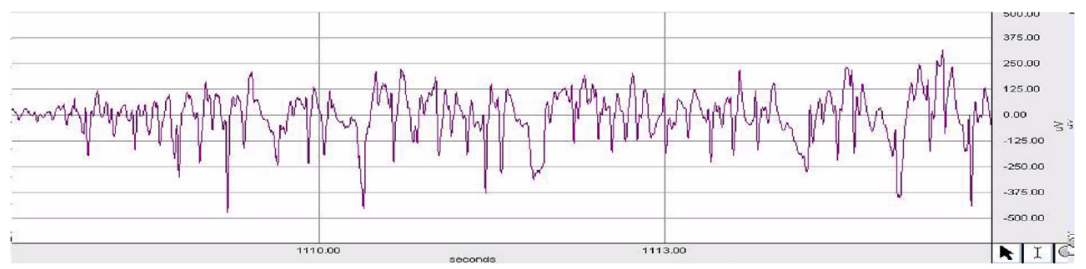

$\mathrm{C}$

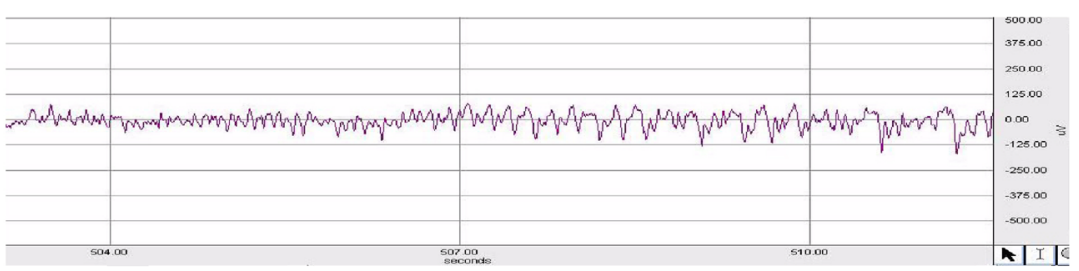

D

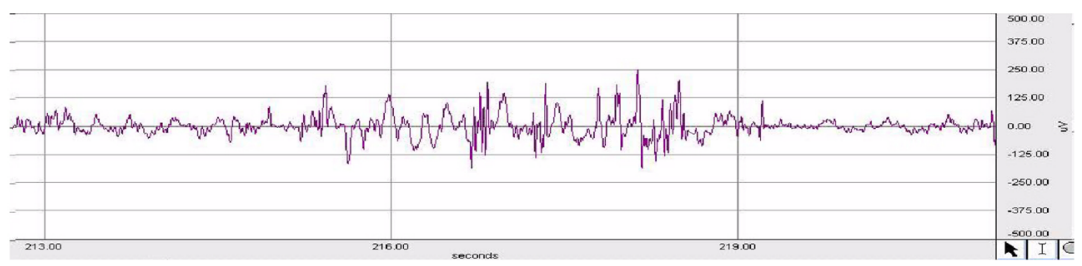

$\mathrm{E}$

The Frequences of SRSs

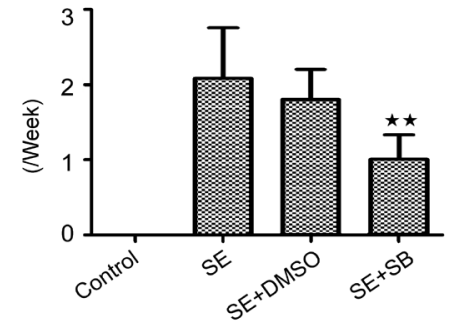

Fig. 1. Spontaneous recurrent seizure (SRS) activities during the chronic period: (A-D) The results of electroencephalogramin groups of control (A), SE (B), SE + DMSO (C) and SE + SB (D). (E) The frequency of SRSs in the chronic period decreased after SB-271046 intervention $\left({ }^{* * *} P<0.001, \mathrm{SE}+\mathrm{SB}\right.$ vs. SE).

Expressions of HTR6, Fyn and p-ERK1/2 at Different Time Points after Induction of SE

The relative protein levels of HTR6, Fyn, and p-ERK1/2 detected after SE operation were significantly higher than those in the control group $(P<0.01)$. Compared to the SE-1W group, all these proteins in the SE-2W group were significantly increased $(P<0.01)$, while there was no significant difference between groups of SE-2W and SE-4W (Fig. 3).

\section{Effects of HTR6 agonist and HTR6/Fyn/ERK1/2 Antagonists on MFS}

As shown in Figure 4, MFS was clearly observable in the CA3 region after operation of SE when compared with the control group $(P<0.001)$. The addition of HTR6 agonist to the healthy rats also accelerated progression of MFS $(P<0.05)$, further validating the 


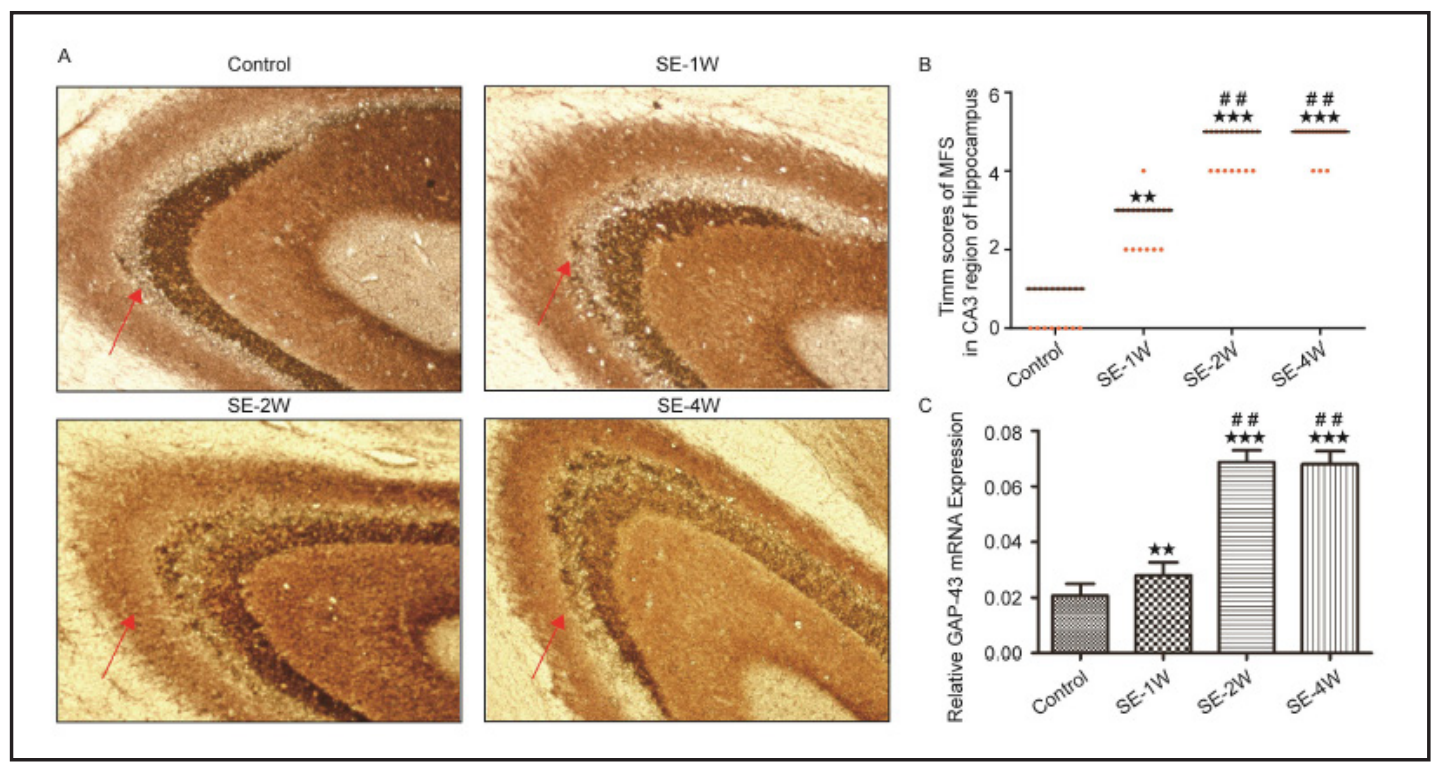

Fig. 2. Timm's staining in the CA3 region at various time points: (A) Brown granules appeared in the stratum pyramidale or stratum oriens, as shown by the black arrows. The phenomenon became increasingly obvious after SE operation and peaked 4 weeks after SE operation. (B) Summarized data showing the mean Timm's scores in the control and SE groups $\left({ }^{* *} P<0.01\right.$, ${ }^{* * *} P<0.001$ vs. control group; \#\#P<0.01 vs. SE$1 W$ ). (C) Quantitative analyses of relative GAP-43 mRNA expression. GAP-43 mRNA expression increased significantly and peaked 2 weeks after SE operation ${ }^{* *} P<0.01,{ }^{* * *} P<0.001$ vs. control group, $\# \# P<0.01$ vs. SE-1W group).

Fig. 3. Timm's staining in the CA3 region at various time points: (A) Brown granules appeared in the stratum pyramidale or stratum oriens, as shown by the black arrows. The phenomenon became increasingly obvious afterSE operation and peaked 4 weeks after SE operation. (B) Summarized data showing the mean Timm's scores in the control and SE groups ( ${ }^{* *} P<0.01,{ }^{* * *} P<0.001$ vs. control group; \#\#P< 0.01 vs. SE-1W). Quantitative analyses of relative GAP-43 mRNA expression. GAP-43

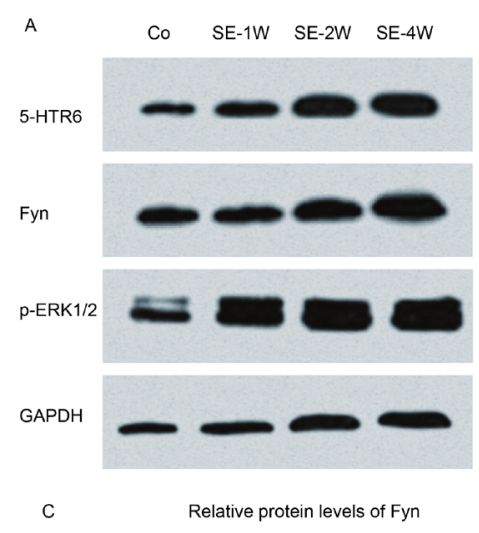

$\mathrm{C}$

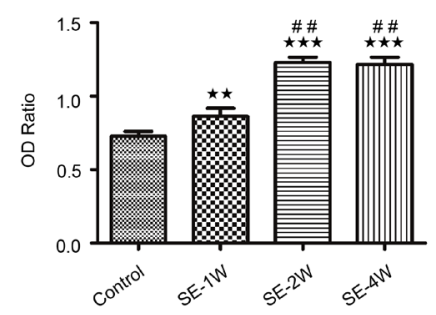
Relative protein levels of 5-HTR6

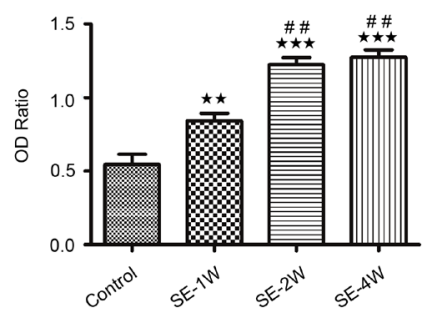

D Relative protein levels of $\mathrm{p}-\mathrm{ERK} 1 / 2$

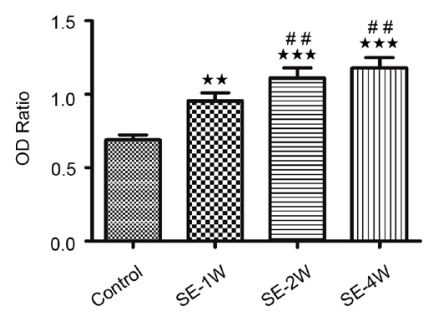

mRNA expression increased significantly and peaked 2 weeks after SE operation $\left({ }^{* *} P<0.01,{ }^{* * *} P<0.001\right.$ vs. control group, $\# \# P<0.01$ vs. SE-1W group).

critical involvement of HTR6 in MFS development. Nevertheless, treatment of SE rats with SB-271046, $\mathrm{PP}_{2}$ and PD-98059 could all significantly decrease their MFS degree $(P<0.01)$. 


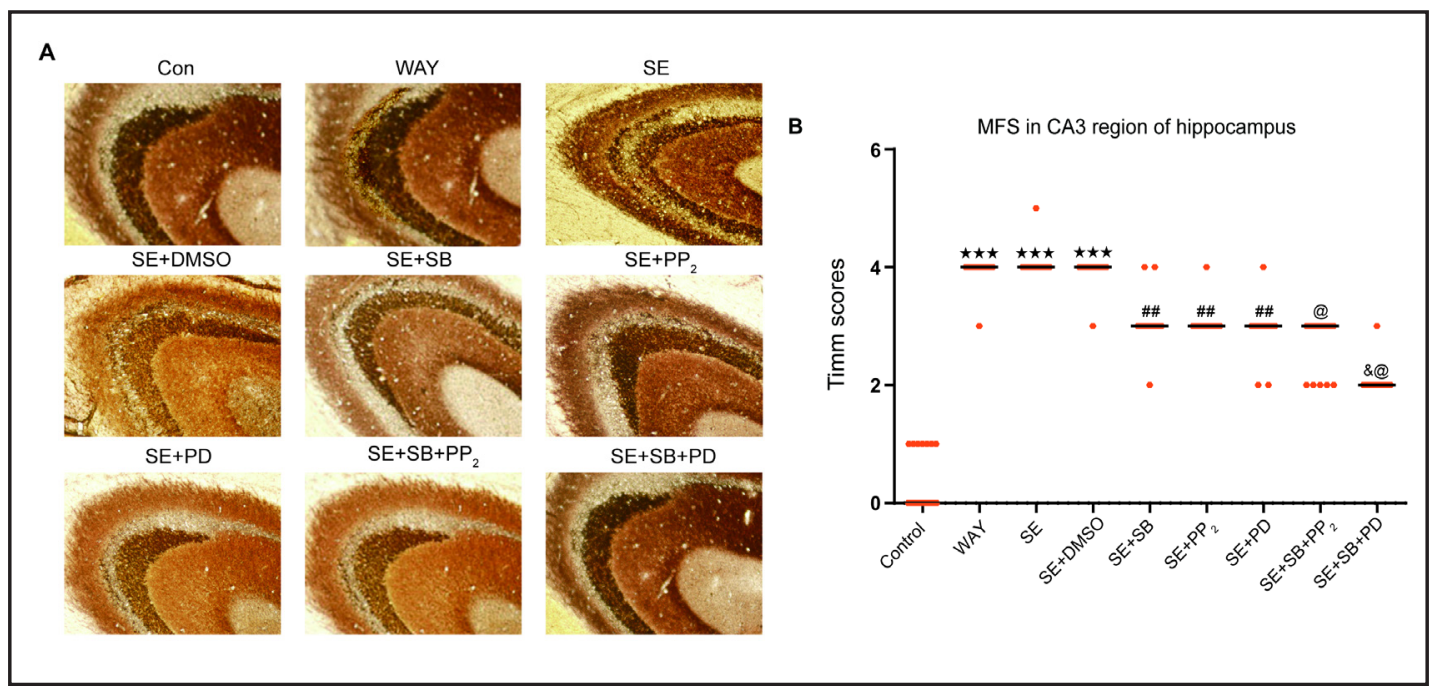

Fig. 4. Expression of HTR6, Fyn and p-ERK1/2 via western blotting at various time points after SE: GAPDH was used as the loading control. B-D showed the relative levels of HTR6, Fyn and p-ERK1/2, respectively. All of these proteins showed significant increases after $\mathrm{SE}$ operation $\left({ }^{* *} P<0.01,{ }^{* * *} P<0.001\right.$ vs. control group; $\# \# P<0.01$ vs. SE-1W group).

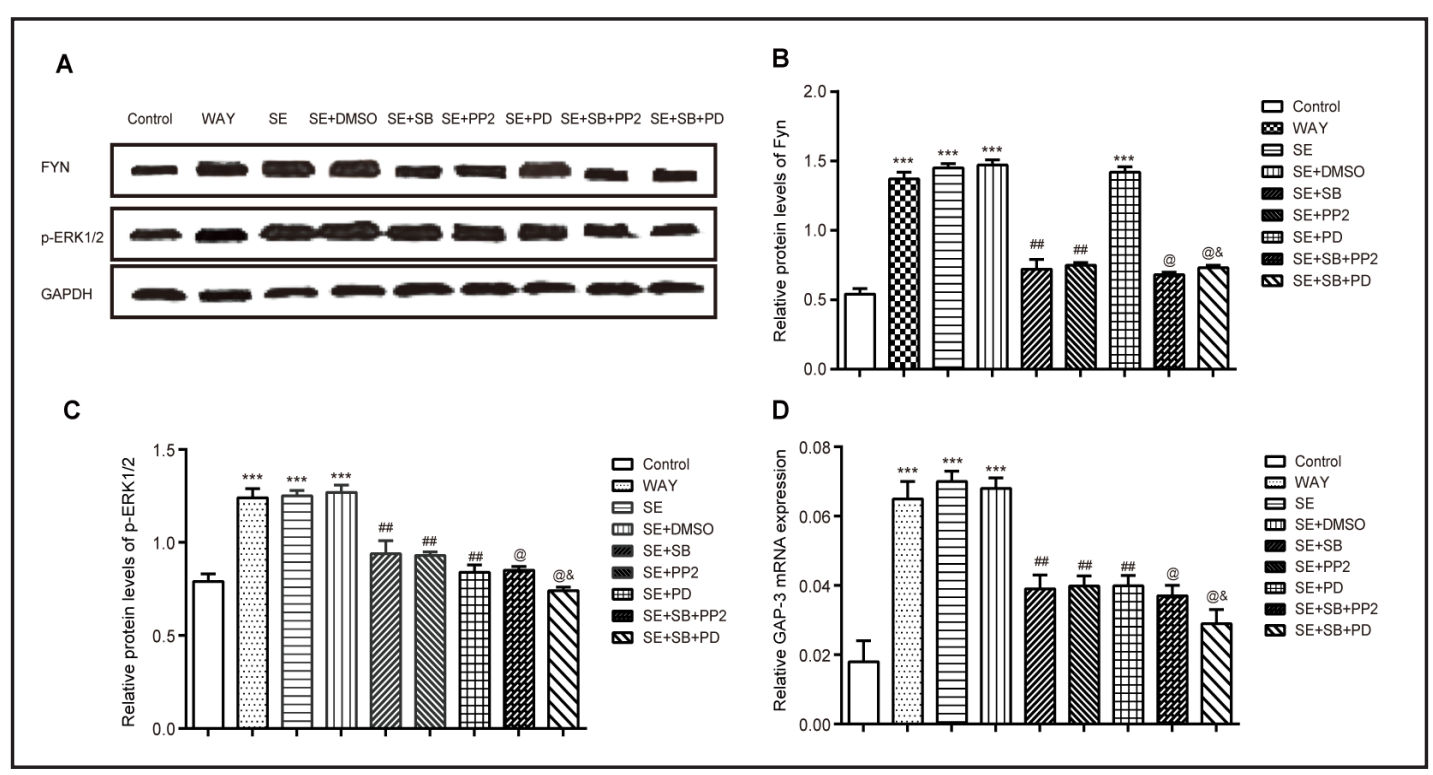

Fig. 5. Effects of HTR6/Fyn/ERK1/2 antagonists on Fyn, p-ERK1/2 and GAP-43 expressions: (A-B) Fyn expression was elevated under treatments of WAY-181187 and SE, yet down-regulated after treatments of SB-271046 or PP2. Fyn expressions displayed no difference between treatments of SE and SE+PD. (C) p-ERK1/2 was significantly increased after treatment of WAY and SE, but it was significantly decreased after treatment with SB-271046, PP2or PD-98059. And SB-271046 combined with PP2or PD-98059 could further reduce p-ERK1/2 expressions ( ${ }^{* * *} P<0.001$ vs. control group; $\# \# P<0.01$ vs. SE group, @P< 0.05 vs. SE + SB group). Combining SB-271046 with PD-98059 produced a stronger reduction than combining SB271046 with PD-98059 ( $\& P<0.05$ vs. SE + SB + PP2group). (D) GAP-43 mRNA expression was significantly increased after SE, clearly decreased after treatment with SB-271046, PP2or PD-98059 intervention, and further inhibited by combining SB-271046 with PP2or PD-98059 (*** $P<0.001$ vs. control group; \#\#P<0.01 vs. SE group, @P< 0.05 vs. SE + SB group). Combining SB-271046 with PD-98059 showed a more marked effect than combining SB-271046 with PD-98059 ( $\& P<0.05$ vs. SE + SB + PP2group). 
Interestingly, combining SB-271046 with $\mathrm{PP}_{2}$ or PD-98059 further decreased the MFS scores compared to SE+SB $(P<0.05)$, and SB + PD significantly blocked MFS in comparison to SB + $\mathrm{PP}_{2}(P<0.05)$.

Effects of HTR6 agonist and HTR6/Fyn/ERK1/2 Antagonists on p-ERK1/2 and GAP-43 mRNA expressions

Expressions of Fyn, p-ERK1/2 and GAP-43 were significantly improved after treatment with WAY $(P<0.05)$, HTR6 (Fig. 5). Besides, Fyn and p-ERK1/2 expressions were significantly increased after SE operation in comparison to the control group $(P<0.001)$. Administration of rats with SB-271046, $\mathrm{PP}_{2}$, or PD-98059 would significantly decrease their internal p-ERK1/2 expressions $(P<0.01)$. Additionally, SB-271046 combined with either $\mathrm{PP}_{2}$ or PD98059 for SE rats would decrease p-ERK1/2 expressions in comparison to SB alone $(P<$ $0.05)$, and $\mathrm{SB}+\mathrm{PD}$ blocked the increased p-ERK1/2 expression more significantly than $\mathrm{SB}$ $+\mathrm{PP}_{2}(P<0.05)$. GAP-43 mRNA expressions exhibited the same trend as the expressions of p-ERK1/2. Nevertheless, slightly different from p-ERK1/2 and GAP-43, Fyn expressions were not affected by treatment of $\mathrm{PD}$, and Fyn expression of $\mathrm{SE}+\mathrm{SB}+\mathrm{PD}$ group was approximate to that of SE+SB group.

\section{Discussion}

Since one-third of seizure patients were refractory to pharmacological therapies [27], novel treatments aimed at remedying this condition were demanded, and hence exploration of the potential mechanisms leading to seizure should still be underway. It was commonly contended that MFS was able to trigger formations of recurrent excitatory synaptic connections and spontaneous seizures [28], and the degree of MFS may reflect severity of the stimulated seizures $[29,30]$. In consequence, this investigation used MFS to signal seizure, and derived results that hippocampal MFS of pilocarpine-induced chronic epileptic rats was intensified in comparison to that of healthy rats. Besides, MFS became increasingly obvious after SRSs and the decrease in SRSs resulting from HTR6 antagonist (i.e. SB) alleviated the phenomenon of MFS. Thus, we conclude that HTR6 could be involved in the progression of MFS, which was related with recurrent seizures.

Furthermore, it has been documented that increased Fyn expressions would possibly induce activation of ERK1/2 to phosphorylated ERK1/2 (p-ERK1/2) through interacting with the carboxyl-terminal region of HTR6 [31, 32]. ERK1/2 that was highly expressed in the central nervous system could affect the formation of MFS by modulating neurotransmitters, neurotropic factors (e.g. GAP-43) and synaptic remodeling (e.g. axon generation) in epileptic models [33]. For example, epileptiform discharge activated p-ERK1/2 cascade and then boosted GAP-43 expressions in cultured rat hippocampal neurons [18]. In sum, the above findings provided exclusive evidence that HTR6 activated downstream ERK1/2 and GAP-43 via a Fyn-dependent pathway in the pathogenesis of epilepsy.

However, what should not be ignored seemed that Fyn and p-ERK1/2 were controlled by more than 5-HTR6, which could be drawn from the results that the synergic effects of $\mathrm{SB}$ and $\mathrm{PD}$ or $\mathrm{PP}_{2}$ on promotion of MFS were obviously larger than the effect of SB alone. According to previous studies, the complex of cellular Prion Protein $\left(\mathrm{PrP}^{\mathrm{C}}\right)$ and AmyloidBeta peptide $(A \beta O)$ could regulate functions of N-methyl-D-aspartate receptor (NMDA-R), thereby contributing much to the pathogenesis of Alzheimer's disease [34-36]. The modified process that affected synaptic plasticity was hypothesized to proceed through activation of Fyn, which participated in restraining hippocampal long-term potentiation (LTP) and phosphorylation of NMDA-R subunits [37-40]. Furthermore, Fyn-modified ERK1/2 was also mediated by other upstream molecules, such as c-Src/Yes, in response to actions of angiotensin II (ANG II) [41]. Apart from the direct control of ERK1/2 by Fyn, $c$-fos that was highly correlated with activation of GAP-43 was also subject to regulation of PKC-controlled ERK1/2 [41]. Hence, although 5-HTR6 was confirmed to develop MFS via regulation of Fyn 
and p-ERK1/2, we could not assert that modulation of p-ERK1/2 was definitely based on the regulation of Fyn. Extra investigations concerning the direct relationship between Fyn and p-ERK1/2 should be explored. Besides, other upstream molecules that could cause the upregulation of Fyn/p and ERK1/2 should also be studied, since they might become potential treatment candidates for seizure.

Despite the achievements, several limitations in this study should be addressed. Firstly, the studied HTR6 was mainly expressed in pyramidal neurons, nonetheless, whether HTR6 that were localized in glutamatergic, GABA ergic, cholinergic or other types of neurons could play a similar role remained unclear [5]. In addition, our study demonstrated that HTR6 expression peaked at the $2^{\text {nd }}$ week within pilocarpine-induced SE rat, while Wang et al. concluded that the expression of HTR6 continuously increased over a period of four weeks [5]. This discrepancy in action effects of pilocarpine may be explained by its different doses for establishment of epileptic models. Finally, various epileptic models may render changes of 5-HTR6 expressions to be different since corresponding targets differed. Specifically, the pilocarpine-induced chronic model targeted Gamma Amino Acid Butyric Acid (GABA) receptors, while other models targeted either kainicacid or N-methyl-D-aspartic acid (NMDA) receptors. Consequently, although we concluded that increased 5-HTR6 expressions may be involved in pathogenesis of pilocarpine-induced chronic epilepsy, further studies were required to confirm whether this finding could be generalized to other epileptic models.

In conclusion, 5-HTR6 may be involved in the progression of MFS by activating p-ERK1/2, Fyn, and GAP-43, which may offer a potential target for restoring the network dysfunction. However, this study was limited by its not detecting frequencies and stages of SRSs in groups of $\mathrm{SE}+\mathrm{PP}_{2}$ and $\mathrm{SE}+\mathrm{PD}$. In fact, if the treatments of $\mathrm{PP}_{2}$ and $\mathrm{PD}$ worked, they might become promising treatment targets for SRS. Therefore, we would further explore whether $\mathrm{PP}_{2}$ and PD could constrain increased SRSs, and additional projects using other animal models were encouraged to determine the detailed relationship between 5-HTR6 and MFS.

\section{Disclosure Statement}

The authors declare no commercial or financial conflict of interest.

\section{Acknowledgments}

The project was funded by the National Natural Science Foundation of China (No. 81371426) Fujian Province Natural Science Foundation Project (No. 2015J01467) and Fujian Province Gerontology Clinical Specialty Construction Project Foundation (No.2015-SLN).

\section{References}

$\checkmark 1$ Kuo LW, Lee CY, Chen JH, Wedeen VJ, Chen CC, Liou HH, Tseng WY: Mossy fiber sprouting in pilocarpineinduced status epilepticus rat hippocampus: a correlative study of diffusion spectrum imaging and histology. Neuroimage 2008;41:789-800.

- Pinheiro PS, Lanore F, Veran J, Artinian J, Blanchet C, Crepel V, Perrais D, Mulle C: Selective block of postsynaptic kainate receptors reveals their function at hippocampal mossy fiber synapses. Cereb Cortex 2013;23:323-331.

- B Buckmaster PS, Ingram EA, Wen X: Inhibition of the mammalian target of rapamycin signaling pathway suppresses dentate granule cell axon sprouting in a rodent model of temporal lobe epilepsy. J Neurosci 2009;29:8259-8269.

4 Lee CY, Jaw T, Tseng HC, Chen IC, Liou HH: Lovastatin modulates glycogen synthase kinase-3beta pathway and inhibits mossy fiber sprouting after pilocarpine-induced status epilepticus. PLoS One 2012;7:e38789. 


\section{Cellular Physiology Cell Physiol Biochem 2017;42:231-241

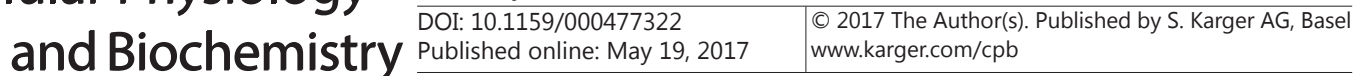

Lin et al.: 5-HTR6 Activated Fyn/p-ERK1/2 Pathway in Chronic Epileptic

-5 Wang L, Lv Y, Deng W, Peng X, Xiao Z, Xi Z, Chen G, Wang X: 5-HT6 Receptor Recruitment of mTOR Modulates Seizure Activity in Epilepsy. Mol Neurobiol 2015;51:1292-1299.

6 Smolders I, Clinckers R, Meurs A, De Bundel D, Portelli J, Ebinger G, Michotte Y: Direct enhancement of hippocampal dopamine or serotonin levels as a pharmacodynamic measure of combined antidepressantanticonvulsant action. Neuropharmacology 2008;54:1017-1028.

$\checkmark 7$ Fujimoto Y, Funao T, Suehiro K, Takahashi R, Mori T, Nishikawa K: Brain serotonin content regulates the manifestation of tramadol-induced seizures in rats: disparity between tramadol-induced seizure and serotonin syndrome. Anesthesiology 2015;122:178-189.

8 Trindade-Filho EM, de Castro-Neto EF, de ACR, Lima E, Scorza FA, Amado D, Naffah-Mazzacoratti Mda G, Cavalheiro EA: Serotonin depletion effects on the pilocarpine model of epilepsy. Epilepsy Res 2008;82:194199.

9 Kobayashi K, Ikeda Y, Sakai A, Yamasaki N, Haneda E, Miyakawa T, Suzuki H: Reversal of hippocampal neuronal maturation by serotonergic antidepressants. Proc Natl Acad Sci U S A 2010;107:8434-8439.

10 Kobayashi K, Ikeda Y, Haneda E, Suzuki H: Chronic fluoxetine bidirectionally modulates potentiating effects of serotonin on the hippocampal mossy fiber synaptic transmission. J Neurosci 2008;28:6272-6280.

11 Meneses A, Perez-Garcia G, Ponce-Lopez T, Castillo C: 5-HT6 receptor memory and amnesia: behavioral pharmacology--learning and memory processes. Int Rev Neurobiol 2011;96:27-47.

12 Carr GV, Lucki I: The role of serotonin receptor subtypes in treating depression: a review of animal studies. Psychopharmacology (Berl) 2011;213:265-287.

13 Da Silva Costa-Aze V, Quiedeville A, Boulouard M, Dauphin F: 5-HT6 receptor blockade differentially affects scopolamine-induced deficits of working memory, recognition memory and aversive learning in mice. Psychopharmacology (Berl) 2012;222:99-115.

14 Codony X, Vela JM, Ramirez MJ: 5-HT(6) receptor and cognition. Curr Opin Pharmacol 2011;11:94-100.

-15 Routledge C, Bromidge SM, Moss SF, Price GW, Hirst W, Newman H, Riley G, Gager T, Stean T, Upton N, Clarke SE, Brown AM, Middlemiss DN: Characterization of SB-271046: a potent, selective and orally active 5-HT(6) receptor antagonist. Br J Pharmacol 2000;130:1606-1612.

16 Yun HM, Kim S, Kim HJ, Kostenis E, Kim JI, Seong JY, Baik JH, Rhim H: The novel cellular mechanism of human 5-HT6 receptor through an interaction with Fyn. J Biol Chem 2007;282:5496-5505.

17 Cain DP, Grant SG, Saucier D, Hargreaves EL, Kandel ER: Fyn tyrosine kinase is required for normal amygdala kindling. Epilepsy Res 1995;22:107-114.

18 Xu ZC, Chen YM, Xu P, Liu H, Xie YL, Zeng KB: Epileptiform discharge upregulates p-ERK1/2, growthassociated protein 43 and synaptophysin in cultured rat hippocampal neurons. Seizure 2009;18:680-685.

19 Gordon T, Tetzlaff W: Regeneration-associated genes decline in chronically injured rat sciatic motoneurons. Eur J Neurosci 2015;42:2783-2791.

20 Ceber M, Sener U, Mihmanli A, Kilic U, Topcu B, Karakas M: The relationship between changes in the expression of growth associated protein-43 and functional recovery of the injured inferior alveolar nerve following transection without repair in adult rats. J Craniomaxillofac Surg 2015;43:1906-1913.

-21 Ying Z, Najm I, Nemes A, Pinheiro-Martins AP, Alexopoulos A, Gonzalez-Martinez J, Bingaman W: Growthassociated protein 43 and progressive epilepsy in cortical dysplasia. Ann Clin Transl Neurol 2014;1:453461.

22 Jia TM, Liu T, Luan B, Li XL, Zhang XL: [Effects of levetiracetam on the expression of NCAM and GAP-43 mRNA in the hippocampus of rats with epilepsy]. Zhongguo Dang Dai Er Ke Za Zhi 2011;13:428-431.

23 Racine RJ: Modification of seizure activity by electrical stimulation. II. Motor seizure. Electroencephalogr Clin Neurophysiol 1972;32:281-294.

24 Lin WH, Huang HP, Lin MX, Chen SG, Lv XC, Che CH, Lin JL: Seizure-induced 5-HT release and chronic impairment of serotonergic function in rats. Neurosci Lett 2013;534:1-6.

25 Budantsev A, Kisliuk OS, Shul'govskii VV, Rykunov DS, Iarkov AV: [The brain in stereotaxic coordinates (a textbook for colleges)]. Zh Vyssh Nerv Deiat Im I P Pavlova 1993;43:1045-1051.

26 Cilio MR, Sogawa Y, Cha BH, Liu X, Huang LT, Holmes GL: Long-term effects of status epilepticus in the immature brain are specific for age and model. Epilepsia 2003;44:518-528.

27 Pati S, Alexopoulos AV: Pharmacoresistant epilepsy: from pathogenesis to current and emerging therapies. Cleve Clin J Med 2010;77:457-467.

28 Sutula TP, Dudek FE: Unmasking recurrent excitation generated by mossy fiber sprouting in the epileptic dentate gyrus: an emergent property of a complex system. Prog Brain Res 2007;163:541-563. 


\section{Cellular Physiology Cell Physiol Biochem 2017;42:231-241

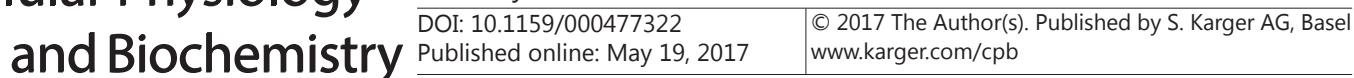

Lin et al.: 5-HTR6 Activated Fyn/p-ERK1/2 Pathway in Chronic Epileptic

29 Hester MS, Danzer SC: Accumulation of abnormal adult-generated hippocampal granule cells predicts seizure frequency and severity. J Neurosci 2013;33:8926-8936.

-30 Huang WJ, Tian FF, Chen JM, Guo TH, Ma YF, Fang J, Dang J, Song MY: GSK-3beta may be involved in hippocampal mossy fiber sprouting in the pentylenetetrazole-kindling model. Mol Med Rep 2013;8:13371342.

-31 Dayer AG, Jacobshagen M, Chaumont-Dubel S, Marin P: 5-HT6 Receptor: A New Player Controlling the Development of Neural Circuits. ACS Chem Neurosci 2015;6:951-960.

-32 Yun HM, Rhim H: The serotonin-6 receptor as a novel therapeutic target. Exp Neurobiol 2011;20:159-168.

-33 Shu Y, Xiao B, Wu Q, Liu T, Du Y, Tang H, Chen S, Feng L, Long L, Li Y: The Ephrin-A5/EphA4 Interaction Modulates Neurogenesis and Angiogenesis by the p-Akt and p-ERK Pathways in a Mouse Model of TLE. Mol Neurobiol 2016;53:561-576.

-34 Shankar GM, Bloodgood BL, Townsend M, Walsh DM, Selkoe DJ, Sabatini BL: Natural oligomers of the Alzheimer amyloid-beta protein induce reversible synapse loss by modulating an NMDA-type glutamate receptor-dependent signaling pathway. J Neurosci 2007;27:2866-2875.

-35 Lacor PN, Buniel MC, Furlow PW, Clemente AS, Velasco PT, Wood M, Viola KL, Klein WL: Abeta oligomerinduced aberrations in synapse composition, shape, and density provide a molecular basis for loss of connectivity in Alzheimer's disease. J Neurosci 2007;27:796-807.

-36 Snyder EM, Nong Y, Almeida CG, Paul S, Moran T, Choi EY, Nairn AC, Salter MW, Lombroso PJ, Gouras GK, Greengard P: Regulation of NMDA receptor trafficking by amyloid-beta. Nat Neurosci 2005;8:1051-1058.

37 Shankar GM, Li S, Mehta TH, Garcia-Munoz A, Shepardson NE, Smith I, Brett FM, Farrell MA, Rowan MJ, Lemere CA, Regan CM, Walsh DM, Sabatini BL, Selkoe DJ: Amyloid-beta protein dimers isolated directly from Alzheimer's brains impair synaptic plasticity and memory. Nat Med 2008;14:837-842.

- 38 Freir DB, Nicoll AJ, Klyubin I, Panico S, Mc Donald JM, Risse E, Asante EA, Farrow MA, Sessions RB, Saibil HR, Clarke AR, Rowan MJ, Walsh DM, Collinge J: Interaction between prion protein and toxic amyloid beta assemblies can be therapeutically targeted at multiple sites. Nat Commun 2011;2:336.

39 Barry AE, Klyubin I, Mc Donald JM, Mably AJ, Farrell MA, Scott M, Walsh DM, Rowan MJ: Alzheimer's disease brain-derived amyloid-beta-mediated inhibition of LTP in vivo is prevented by immunotargeting cellular prion protein. J Neurosci 2011;31:7259-7263.

40 Nakazawa T, Komai S, Tezuka T, Hisatsune C, Umemori H, Semba K, Mishina M, Manabe T, Yamamoto T: Characterization of Fyn-mediated tyrosine phosphorylation sites on GluR epsilon 2 (NR2B) subunit of the N-methyl-D-aspartate receptor. J Biol Chem 2001;276:693-699.

41 Godeny MD, Sayeski PP: ANG II-induced cell proliferation is dually mediated by c-Src/Yes/Fyn-regulated ERK1/2 activation in the cytoplasm and PKCzeta-controlled ERK1/2 activity within the nucleus. Am J Physiol Cell Physiol 2006;291:C1297-1307. 